Article

\title{
A Schiff-Base Modified Pt Nano-Catalyst for Highly Efficient Synthesis of Aromatic Azo Compounds
}

\author{
Yanyan Teng, Xinkui Wang *, Min Wang, Qinggang Liu, Yuqing Shao, Haomeng Li, \\ Changhai Liang, Xiao Chen 1 and Huilong Wang *
}

School of Chemistry, Dalian University of Technology, Dalian 116024, China; 2637259148@mail.dlut.edu.cn (Y.T.); wangmin@dlut.edu.cn (M.W.); liuqinggang@mail.tsinghua.edu.cn (Q.L.);

yuqingshao1996@mail.dlut.edu.cn (Y.S.); lihaomeng@mail.dlut.edu.cn (H.L.);

changhai@dlut.edu.cn (C.L.); xiaochen@dlut.edu.cn (X.C.)

* Correspondence: wangxinkui@dlut.edu.cn (X.W.); hlwang@dlut.edu.cn (H.W.); Tel.: +86-411-84986073 (X.W.)

Received: 21 March 2019; Accepted: 30 March 2019; Published: 4 April 2019

check for updates

\begin{abstract}
A Schiff-base modified Pt nano-catalyst was prepared via one-pot aldimine condensation and then impregnation-reduction of a platinum precursor, in which the Pt nanoparticles (NPs) with an average size of $2.3 \mathrm{~nm}$ were highly dispersed on the support. The as-prepared catalyst exhibited excellent activity and selectivity in the hydrogenation coupling synthesis of aromatic azo compounds from nitroaromatic under mild conditions. The strong metal-support interaction derived from the coordination of nitrogen sites on Schiff-base to Pt NPs enables stabilizing the Pt NPs and achieving the catalytic recyclability. The scheme can also tolerate various functional groups and offer an efficient method for the green synthesis of aromatic azo compounds.
\end{abstract}

Keywords: Pt nano-catalyst; Schiff-base; aromatic azo compounds (Aazo); nitroaromatic hydrogenation

\section{Introduction}

Aromatic azo compounds (Aazo) are important raw materials, which are widely used in the fields of pigments [1-3], radical reaction initiators [4-6], food additives [7,8], electronic devices [9-12], and drugs [13-16]. The industrial production of Aazo is achieved by the azo-coupling reaction between a diazonium salt and an electron-rich arene, in which stoichiometric amounts of nitrite salts are used, therefore generating large amounts of dangerous wastes of diazonium salts in this process [17-19]. Other methods, including the oxidation of anilines by transition metals, the reduction of nitroaromatics by stoichiometric amounts of metals, and the rearrangement of aromatic azoxy compounds, have also been developed for the synthesis of Aazo [20-25]. However, these conventional procedures generally require harsh reaction conditions or a long reaction time. Recently, the catalytic reduction of nitroaromatics to Aazo over noble metal catalysts system has been widely studied. For example, Corma et al. reported the Aazo formation from nitroaromatics via a one-pot, two-step reaction using $\mathrm{Au} / \mathrm{TiO}_{2}$ [26]. Gu et al. reported Pt nanowires and Pd nanoclusters as efficient catalysts could promote the synthesis of Aazo from the corresponding nitroaromatics in the alkaline condition [27-29]. Cao et al. reported the synthesis of Aazo by hydrogenative coupling of nitroarenes over $\mathrm{Au} / \mathrm{Mg}$-Al hydrotalcite catalyst without any external additives [30]. Although the catalytic synthesis of Aazo derivatives has achieved high selectivity and good yields, the catalytic efficiency of the noble metal catalysts (the average turnover frequency (TOF) typically less than $300 \mathrm{~h}^{-1}$ ), at mild reaction conditions, is still needed to improve for the application in industry. Hence, the development of a more efficient heterogeneous catalytic synthetic procedure is highly desirable. 
For supported metal catalysts, the support not only disperses the active sites but also modifies the electronic properties of the metals. Furthermore, the support can also provide an active site for the reactant activation and affect the product desorption. Previous studies have shown that nitro groups could be easily adsorbed on basic or reducible supports [31,32]. It is promising to develop a novel support to tune the catalytic activity in the hydrogenation of nitroaromatics. For example, Pt NPs immobilized on nitrogen-doped carbon nanotubes showed improved catalytic performance in the hydrogenation of nitrobenzene to anilines under mild conditions [33].

Herein, a Schiff-base modified silica-supported Pt catalyst has been prepared for the hydrogenation of nitroaromatics to Aazo. The presence of Schiff-base groups greatly enhances the catalytic activity, selectivity, and stability. The highest yield achieved is ca. $91.1 \%$ for $4,4^{\prime}$-dichloroazobenzene (DCAB) over $\mathrm{Pt}_{0.5} / \mathrm{SiO}_{2}$-Schiff catalyst with the average TOF up to $2601 \mathrm{~h}^{-1}$. The detailed characterization of the structural and electronic properties of the Pt NPs by High-angle annual dark-field scanning transmission electron microscopy (HAADF-STEM), X-ray diffraction (XRD), Fourier transform infrared spectroscopy (FT-IR) and X-ray photoelectron (XPS) spectroscopy reveal "the role of Schiff base".

\section{Results and Discussion}

\subsection{Catalysts Characterization}

XRD patterns of the samples are shown in Figure 1. For the fresh $\mathrm{Pt}_{0.5} / \mathrm{SiO}_{2}$ catalyst, besides a broad peak ascribed to the $\mathrm{SiO}_{2}$, there are two diffraction peaks at $2 \theta=39.9^{\circ}$ and $46.3^{\circ}$ corresponding to the (1 111$)$ and (2 $\left.\begin{array}{lll}2 & 0\end{array}\right)$ planes of the face-centered cubic structures of platinum (ICDD PDF No. 64-0802), respectively (Figure 1a) [34]. According to Scherrer's equation, the particle size of Pt NPs is estimated to be ca. $3.8 \mathrm{~nm}$. However, only a very weak and broad peak of $\mathrm{Pt}$ at $39.8^{\circ}$ is discernible for the fresh $\mathrm{Pt}_{0.5} / \mathrm{SiO}_{2}$-Shiff catalyst (Figure 1c), indicating Pt NPs with small particles are highly dispersed on the support. In agreement with the XRD results, the HAADF-STEM image (Figure 2a) shows that the size of Pt NPs on the $\mathrm{Pt}_{0.5} / \mathrm{SiO}_{2}$ is ca. $3.2 \pm 1.0 \mathrm{~nm}$. However, in the case of $\mathrm{Pt}_{0.5} / \mathrm{SiO}_{2}$-Shiff, that is $2.3 \pm 0.8 \mathrm{~nm}$ (Figure 2c).

The FT-IR characterization of the fresh $\mathrm{Pt}_{0.5} / \mathrm{SiO}_{2}$ and $\mathrm{Pt}_{0.5} / \mathrm{SiO}_{2}$-Shiff has been performed to clarify the surface moieties of the catalysts. As seen in Figure 3, for the $\mathrm{Pt}_{0.5} / \mathrm{SiO}_{2}$ catalyst, only characteristic absorption bands for the pure $\mathrm{SiO}_{2}$ are detected, that is, the band at $1107 \mathrm{~cm}^{-1}$ is assigned to the antisymmetric stretching vibration of the Si-O. In contrast, for the $\mathrm{Pt}_{0.5} / \mathrm{SiO}_{2}$-Shiff catalyst, additional bands at 2869 and $2927 \mathrm{~cm}^{-1}$ can be assigned to the symmetric and asymmetric vibrations of the $-\mathrm{CH}_{2}$ groups. The N-H moiety vibration band is observed at $934 \mathrm{~cm}^{-1}$, which is attributed to the uncondensed amino group. In addition, the appearance of the Schiff base $(-\mathrm{N}=\mathrm{C})$ band at $1695 \mathrm{~cm}^{-1}$ indicates the successful graft of Schiff base on the surface of $\mathrm{SiO}_{2}$ support [35].

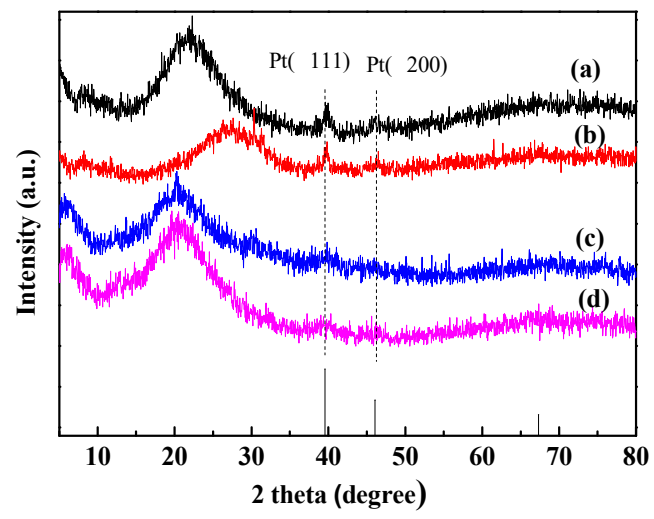

Figure 1. XRD patterns of $\mathrm{Pt}_{0.5} / \mathrm{SiO}_{2}$ before (a) and after reaction (b), as well as $\mathrm{Pt}_{0.5} / \mathrm{SiO}_{2}-\mathrm{Shiff}$ before (c) and after reaction $(\mathbf{d})$. 

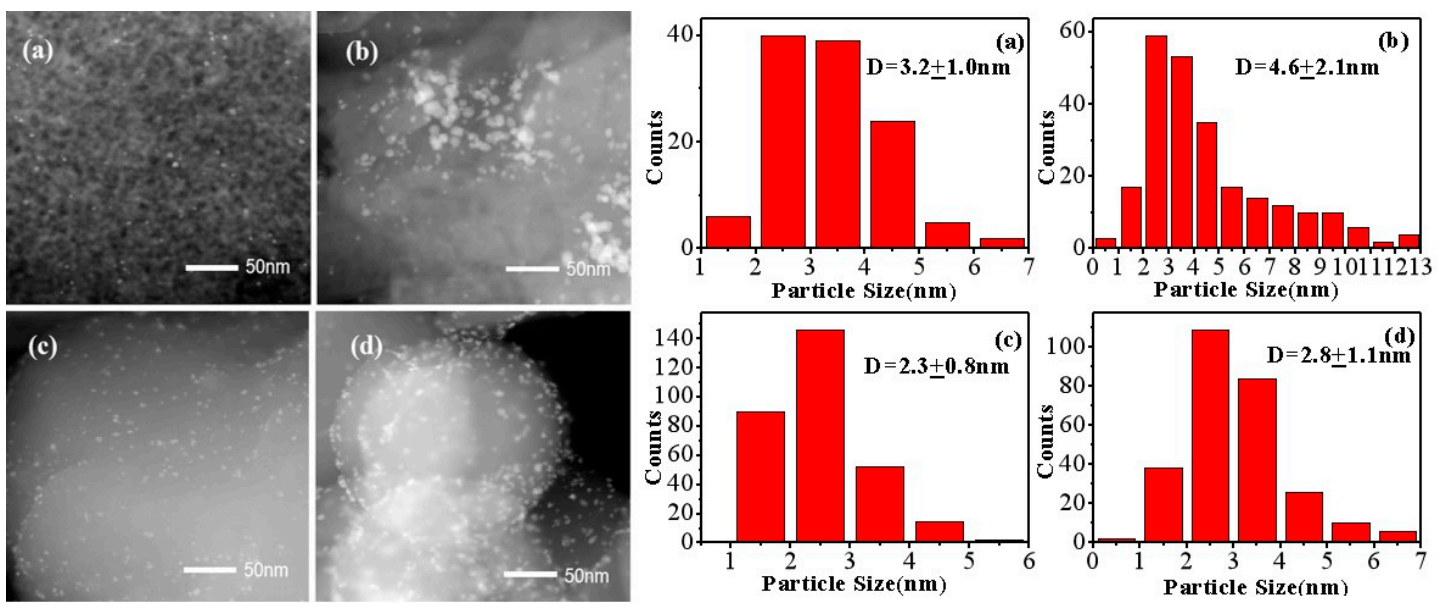

Figure 2. HAADF-STEM images and corresponding size distribution of $\mathrm{Pt}_{0.5} / \mathrm{SiO}_{2}$ before (a) and after reaction (b), as well as $\mathrm{Pt}_{0.5} / \mathrm{SiO}_{2}$-Shiff before (c) and after reaction (d).

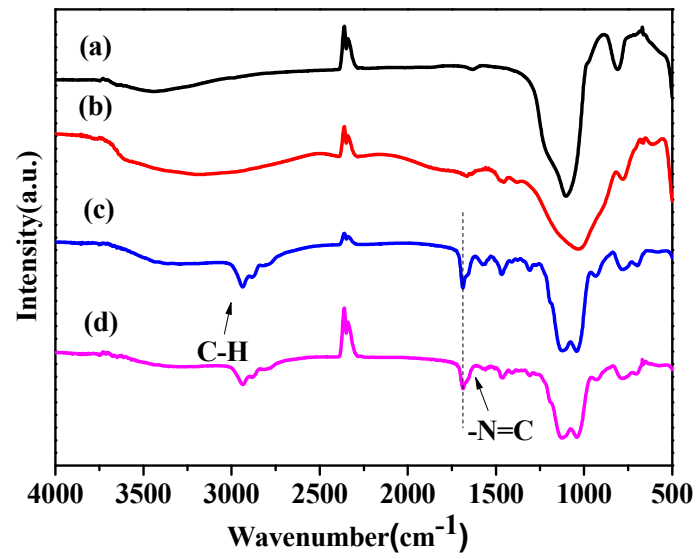

Figure 3. FT-IR spectra of $\mathrm{Pt}_{0.5} / \mathrm{SiO}_{2}$ before (a) and after reaction (b), as well as $\mathrm{Pt}_{0.5} / \mathrm{SiO}_{2}-\mathrm{Shiff}_{\text {before }}$ (c) and after reaction (d).

XPS was further performed to characterize the electronic properties of Pt NPs. For the fresh $0.5 \mathrm{wt} \% \mathrm{Pt} / \mathrm{SiO}_{2}$ (Figure 4a), the binding energy centered at 74.39 and $71.19 \mathrm{eV}$ can be assigned to $\mathrm{Pt} 4 \mathrm{f}_{5 / 2}$ and $\mathrm{Pt}_{7 \mathrm{f}_{7 / 2}}$ of $\mathrm{Pt}^{0}$, respectively. While for the $0.5 \mathrm{wt} \% \mathrm{Pt} / \mathrm{SiO}_{2}$-Shiff catalyst (Figure $4 \mathrm{~b}$ ), the binding energy of $\mathrm{Pt}_{4} \mathrm{f}_{5 / 2}$ and $\mathrm{Pt}_{4} \mathrm{f}_{7 / 2}$ of $\mathrm{Pt}^{0}$ shifted to 73.89 and $70.49 \mathrm{eV}$. Such a negative shift can be attributed to the electron donation from nitrogen atom to $\mathrm{Pt}[36,37]$. Therefore, there is a strong interaction between the Pt NPs and the organic groups on $\mathrm{SiO}_{2}$-Schiff.

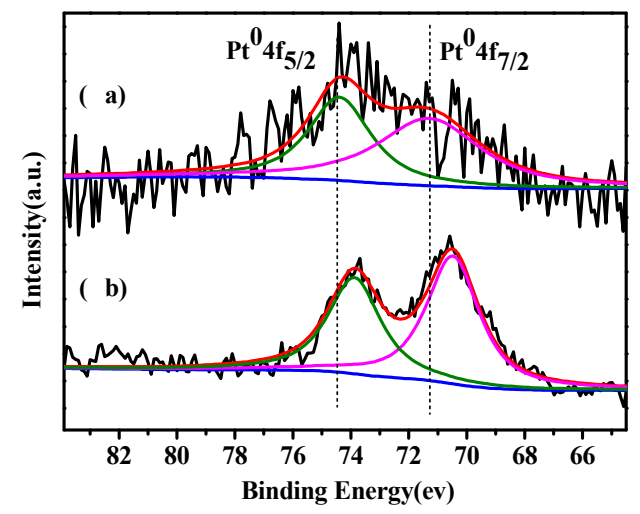

Figure 4. Core level XPS spectra in $\mathrm{Pt} 4 \mathrm{f}$ regions of $\mathrm{Pt}_{0.5} / \mathrm{SiO}_{2}$ (a) and $\mathrm{Pt}_{0.5} / \mathrm{SiO}_{2}$-Schiff (b) catalysts. 


\subsection{Catalytic Activity}

The catalytic performance of the as-synthesized Pt nano-catalysts was evaluated in the hydrogenation of $p$-chloronitrobenzene ( $p$-CNB), the hydrogenation reaction is shown in Scheme 1 . As shown in Table 1, under mild hydrogenation conditions, i.e., $0.5 \mathrm{MPa}$ of $\mathrm{H}_{2}$ pressure in ethanol at $50{ }^{\circ} \mathrm{C}$ and $\mathrm{KOH}$ as additives, the $\mathrm{Pt}_{0.5} / \mathrm{SiO}_{2}$-Schiff shows an excellent hydrogenation activity and azo selectivity, with a yield of $91.1 \%$ at the initial $30 \mathrm{~min}$. The average TOF over $\mathrm{Pt}_{0.5} / \mathrm{SiO}_{2}$-Schiff catalyst is up to $2601 \mathrm{~h}^{-1}$ (Table 1, entry 3). For comparison, the $\mathrm{Pt}_{0.5} / \mathrm{SiO}_{2}$ catalyst prefers to the formation of $4,4^{\prime}$-dichloroazoxybenzene (DCAOB) in a yield of ca. $79.0 \%$ (Table 1 , entry 1 ).

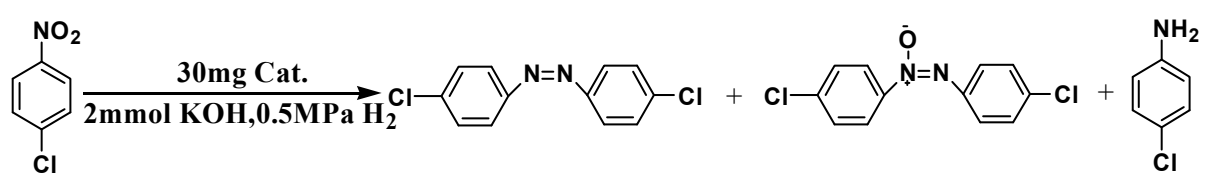

Scheme 1. Hydrogenation of $p$-chloronitrobenzene ( $p$-CNB) over different catalysts.

Table 1. Hydrogenation of $p$-chloronitrobenzene ( $p$-CNB) to $4,4^{\prime}$-dichloroazobenzene (DCAB) over different catalysts.

\begin{tabular}{cccccc}
\hline \multirow{2}{*}{ Entry } & \multirow{2}{*}{ Catalyst } & Conv. (\%) & \multicolumn{3}{c}{ Sel. (\%) } \\
\cline { 4 - 5 } & & & DCAB & DCAOB & $p$-CNA \\
\hline 1 & $\mathrm{Pt}_{0.5} / \mathrm{SiO}_{2}$ & 92.4 & 12.1 & 85.5 & 2.4 \\
$2^{\mathrm{a}}$ & $\mathrm{Pt}_{0.5} / \mathrm{SiO}_{2}$ & 10.6 & - & 94.1 & 5.9 \\
3 & $\mathrm{Pt}_{0.5} / \mathrm{SiO}_{2}-\mathrm{Schiff}$ & 99.0 & 92.1 & 4.7 & 3.2 \\
$4^{\mathrm{a}}$ & $\mathrm{Pt}_{0.5} / \mathrm{SiO}_{2}$-Schiff & 98.6 & 89.1 & 5.8 & 5.1 \\
$5^{\mathrm{b}}$ & $\mathrm{Pt}_{0.5} / \mathrm{SiO}_{2}$-Schiff & 98.2 & 87.1 & 7.0 & 5.9 \\
6 & $\mathrm{Pt}_{0.3} / \mathrm{SiO}_{2}$-Schiff & 97.2 & 57.0 & 40.1 & 2.9 \\
7 & $\mathrm{Pt}_{0.8} / \mathrm{SiO}_{2}$-Schiff & 100 & 93.0 & 2.1 & 4.9 \\
\hline
\end{tabular}

Reaction conditions: $p$-CNB $(1 \mathrm{mmol})$, catalyst $(30 \mathrm{mg}), 0.5 \mathrm{MPa} \mathrm{H}_{2}, 2 \mathrm{mmol} \mathrm{KOH}$, ethanol $(5 \mathrm{~mL}), 50{ }^{\circ} \mathrm{C}, 0.5 \mathrm{~h}$.

${ }^{\text {a }}$ Catalyst was filtered off after the 1st reaction cycle, then the substrate was added for the second reaction cycle.

$\mathrm{b}$ Catalyst after the 2 nd reaction cycle was adopted.

In addition, the $\mathrm{Pt} / \mathrm{SiO}_{2}$-Schiff catalyst presents much better stability than that of the $\mathrm{Pt} / \mathrm{SiO}_{2}$ catalyst, and only a slight decrease in catalytic efficiency is found in the two successive cycles. However, the catalytic activity of $\mathrm{Pt}_{0.5} / \mathrm{SiO}_{2}$ catalyst decreases obviously in cycle experiment (conversion from 92.6 to $10.6 \%$ ) compared with that of the $\mathrm{Pt}_{0.5} / \mathrm{SiO}_{2}$-Schiff catalyst. To understand the unexpected catalytic performance of the $\mathrm{Pt} / \mathrm{SiO}_{2}$-Schiff catalyst, we have made a careful comparison of the characterization of the two samples. The inductively coupled plasma-atomic emission spectroscopy (ICP-AES) results show that the $\mathrm{Pt}$ loading for the $\mathrm{Pt}_{0.5} / \mathrm{SiO}_{2}$ catalyst has a great decrease from 0.48 to $0.31 \%$ after one cycle. However, the metal loading of the $\mathrm{Pt}_{0.5} / \mathrm{SiO}_{2}$-Schiff catalyst keeps almost constant after the reaction. The presence of Schiff-base will prevent the leaching of platinum during the reaction process. No obvious change of particle size and peak position are observed in the XRD pattern of the spent $\mathrm{Pt}_{0.5} / \mathrm{SiO}_{2}$-Schiff (Figure 1), which indicates that $\mathrm{Pt}_{0.5} / \mathrm{SiO}_{2}$-Schiff catalyst has better alkali resistance due to the Schiff base functional group on the surface. While for the used $\mathrm{Pt}_{0.5} / \mathrm{SiO}_{2}$ catalyst, the peak position of the silica is slightly shifted because potassium silicate (ICDD PDF No. 48-0866) is formed via the reaction of $\mathrm{SiO}_{2}$ support with $\mathrm{KOH}$. Correspondingly, as shown in the HAADF-STEM images, the stability of $\mathrm{Pt}_{0.5} / \mathrm{SiO}_{2}$-Schiff is much better than that of $\mathrm{Pt}_{0.5} / \mathrm{SiO}_{2}$ catalyst. The Pt particle size of the spent $\mathrm{Pt}_{0.5} / \mathrm{SiO}_{2}-\mathrm{Schiff}$ has an average size of $2.8 \pm 1.1 \mathrm{~nm}$ (Figure 2d), while the Pt particle size of the spent $\mathrm{Pt}_{0.5} / \mathrm{SiO}_{2}$ is ca. $4.6 \mathrm{~nm}$ with some bigger particles even larger than $10 \mathrm{~nm}$ (Figure $2 \mathrm{~b}$ ). The enhanced activity and stability of $\mathrm{Pt} / \mathrm{SiO}_{2}$-Schiff can be attributed to the strong interaction between the organic groups around and Pt NPs, which keeps the catalytic efficiency of active sites in the reaction.

The effect of $\mathrm{Pt}$ loadings in the $\mathrm{Pt} / \mathrm{SiO}_{2}$-Schiff catalyst for the hydrogenation of $p$-CNB has also been investigated. The ICP-AES results show that the actual loadings of $\mathrm{Pt}$ are $0.76,0.48$ and $0.28 \mathrm{wt} \%$ 
for $\mathrm{Pt}_{0.8} / \mathrm{SiO}_{2}$-Shiff, $\mathrm{Pt}_{0.5} / \mathrm{SiO}_{2}$-Shiff, and $\mathrm{Pt}_{0.3} / \mathrm{SiO}_{2}$-Shiff, respectively. TEM images of $\mathrm{Pt}_{0.8} / \mathrm{SiO}_{2}$-Shiff, $\mathrm{Pt}_{0.5} / \mathrm{SiO}_{2}$-Shiff, and $\mathrm{Pt}_{0.3} / \mathrm{SiO}_{2}$-Shiff show the similar metal particle size, 2.6, 2.2, and $2.4 \mathrm{~nm}$, respectively, as shown in Figure S1. $\mathrm{N}_{2}$-physical adsorption results show that these catalyst samples have the same specific surface area (ca. $18 \mathrm{~m}^{2} \times \mathrm{g}^{-1}$ ). Under the same reaction conditions, the $\mathrm{Pt}_{0.3} / \mathrm{SiO}_{2}$-Schiff catalyst presents a relatively low selectivity due to the lowest Pt content. However, the selectivity to DCAB can be reached to $90 \%$ after extending the reaction time to $1 \mathrm{~h}$.

Generally, the catalytic activity and selectivity are sensitive to the base employed in the formation of Aazo [27-29,38-41]. In our results, the amount and strength of the base have also a great influence on the catalytic nitroaromatic hydrogenation. Without the presentation of base, the $p$-chloroaniline ( $p$-CNA) is the main product (with a selectivity of $97.3 \%$ ) at $96.5 \%$ conversion of nitrobenzene. Once the base was added in the reaction system, even with a weak base, such as $\mathrm{K}_{2} \mathrm{CO}_{3}$ and $\mathrm{Na}_{2} \mathrm{CO}_{3}, \mathrm{DCAOB}$ and $p$-CNA would become the main products. As a strong base, such as $\mathrm{KOH}$, was used in the reaction, $\mathrm{DCAB}$ was then served as the main product, suggesting that a strong base was indispensable in the course of $\mathrm{DCAB}$ formation. The basic additive changes the reaction pathway of the nitroaromatic hydrogenation, in which the dehydration coupling reaction of the aromatic hydroxylamine compound with the aromatic nitroso compound to form an oxygen azo compound is promoted. Subsequently, the oxygen azo compound is further hydrogenated to form an azo compound, enhancing the selectivity to the DCAB. In addition, the amount of $\mathrm{KOH}$ significantly affects the product selectivity (Table 1), and the superior yield (91.1\%) of DCAB is achieved when 2.0 equivalents of $\mathrm{KOH}$ is used, which is the most effective way so far for the azobenzene synthesis.

Solvent effects were also investigated under similar reaction conditions (Table 2). In comparison with other commonly used solvents, our results suggest that ethanol serves as the best solvent for the generation of DCAB (91.1\% yield). The reactions in $p$-xylene, toluene, $n$-heptane show a relatively low activity, with DCAOB as a predominant product, which is the intermediate in the DCAB formation. Generally, less polar protic solvents, such as methanol, ethanol, and $i$-propanol, result in the desired product of DCAB. It has been widely reported that the protic solvents could be served as hydrogen donors in hydrogenation reactions. Therefore, the hydrogen transfer process in protic solvents benefits the hydrogenation involved in the DCAB formation reaction.

Table 2. Effect of solvent and base on the coupling reactions of $p$-CNB.

\begin{tabular}{|c|c|c|c|c|c|c|}
\hline \multirow{2}{*}{ Entry } & \multirow{2}{*}{ Solvent } & \multirow{2}{*}{ Base } & \multirow{2}{*}{ Conv. (\%) } & \multicolumn{3}{|c|}{ Sel. (\%) } \\
\hline & & & & DCAB & DCAOB & $p$-CNA \\
\hline 1 & ethanol & - & 96.5 & 0.3 & 2.4 & 97.3 \\
\hline 2 & ethanol & $\mathrm{K}_{2} \mathrm{CO}_{3}$ (1 eqv.) & 100 & 8.9 & 52.9 & 38.2 \\
\hline 3 & ethanol & $\mathrm{Na}_{2} \mathrm{CO}_{3}$ (1 eqv.) & 98.2 & 6.2 & 27.1 & 66.7 \\
\hline 4 & ethanol & $\mathrm{KOH}(0.5$ eqv.) & 96.5 & 66.2 & 24.4 & 9.4 \\
\hline 5 & ethanol & $\mathrm{KOH}$ (1 eqv.) & 97.8 & 78.8 & 10.4 & 10.8 \\
\hline 6 & ethanol & $\mathrm{KOH}$ (2 eqv.) & 99.0 & 92.1 & 4.7 & 3.2 \\
\hline 7 & ethanol & $\mathrm{KOH}$ (3 eqv.) & 98.9 & 88.1 & 6.8 & 5.1 \\
\hline 8 & methanol & $\mathrm{KOH}$ (2 eqv.) & 86.2 & 37.4 & 51.6 & 11.0 \\
\hline 9 & $i$-propanol & $\mathrm{KOH}$ (2 eqv.) & 99.7 & 90.9 & 3.4 & 5.7 \\
\hline 10 & toluene & $\mathrm{KOH}$ (2 eqv.) & 8.1 & 5.7 & 88.3 & 6.0 \\
\hline 11 & $p$-xylene & $\mathrm{KOH}$ (2 eqv.) & 6.2 & 49.5 & 43.2 & 7.3 \\
\hline 12 & n-heptane & $\mathrm{KOH}$ (2 eqv.) & 14.2 & 12.1 & 43.1 & 44.8 \\
\hline
\end{tabular}

Reaction conditions: $p$-CNB $(1 \mathrm{mmol})$, catalyst $(30 \mathrm{mg}), 0.5 \mathrm{MPa} \mathrm{H}_{2}$, Solvent $(5 \mathrm{~mL}), 50{ }^{\circ} \mathrm{C}, 0.5 \mathrm{~h}$.

To explore the reaction mechanism, the evolution of product distribution was monitored with the reaction time (Figure 5). As we can see, the DCAOB intermediate was predominant at the initial stage, which is further transformed into DCAB. The other hydrogenative intermediates, such as nitrosobenzene and phenylhydroxylamine, are not detected. Based on the above experimental results, the mechanism of the hydrogenation of $p$-CNB to the corresponding DCAB is proposed in Figure 6, which is consistent with 
the literature report [31,42]. The Schiff base promotes the adsorption of $p-\mathrm{CNB}$, and the Pt NPs are served as active sites to activate $\mathrm{H}_{2}$. The $\mathrm{H}$ on the Pt surface reacts with the adsorbed $p$-CNB to generate $p$-CNA, which would be converted to 4-chloro- $N$-hydroxybenzenamine. This 4-chloro- $N$-hydroxybenzenamine can be easily reduced to aniline under a neutral condition, and no coupling product was detected in our experiments. However, when a base is added, the generated 4-chloro- $N$-hydroxybenzenamine will quickly couple with nitrosobenzene to form $4,4^{\prime}$-dichloro- $N, N^{\prime}$-dihydroxy-diphenylhydrazine. This dihydroxy intermediate is then dehydrated to give DCAOB and further hydrogenated to DCAB under strong alkali environment. As a result, DCAB is the only observed coupling product.

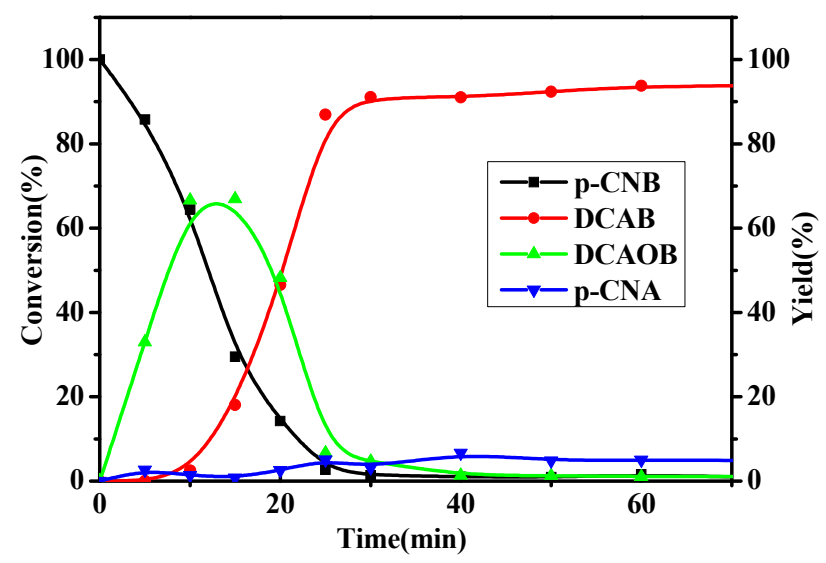

Figure 5. Substrate and product concentration profiles as a function of the reaction time.



Figure 6. The mechanism of the hydrogenation of $p$-CNB to the corresponding DCAB.

To confirm our proposed mechanism, a serial experiment of the hydrogenation of DCAOB and DCAB was performed. Indeed, hydrogenation of DCAOB to DCAB does not occur under weakly alkaline conditions even for a long period reaction time. With a strong base, DCAOB can be readily converted into DCAB with a high yield $(98 \%)$ within $30 \mathrm{~min}$. While the generated DCAB could not continue to be hydrogenated to $4,4^{\prime}$-dichlorohydrazobenzene or $p$-CNA under the given condition. As a result, $\mathrm{DCAB}$ is the major product in the selective hydrogenation of $p$-CNB reaction under strongly basic condition.

To demonstrate the general applicability of this $\mathrm{Pt} / \mathrm{SiO}_{2}$-Schiff catalyst, a series of nitroaromatic compounds in the synthesis of Aazo (Scheme 2) were tested. As shown in Table 3, most of the substituted nitrobenzenes can result in good performance, especially for the compounds with the presence of electron-withdrawing substituents. With an electron donative group such as alkyl (methyl), arylamine (a yield of 49.7\%) is the predominant by-product. While the yield of Aazo can up to $86.1 \%$ when $i$-propanol is used as a solvent and the reaction temperature is raised to $90^{\circ} \mathrm{C}$. The unsubstituted nitrobenzenes are relatively inert in the Aazo formation at the given conditions $\left(50{ }^{\circ} \mathrm{C}, 0.5 \mathrm{MPa} \mathrm{H}_{2}\right)$, and the major by-product is azoxybenzene (yield 58.7\%). However, it can convert to azobenzene with a yield as high as $84.7 \%$ at the higher reaction temperature $\left(90^{\circ} \mathrm{C}\right)$. Moreover, steric properties of the 
substituent also significantly affect the reaction. Specifically, the yield of $p$-substituted azo arene is higher than that of the corresponding $m$-substituted azo arene (Table 3, entry 5 and 6). Halogenated nitroarenes can be readily converted to corresponding azo compounds without any dehalogenation, while a side reaction is often unavoided in the conventional hydrogenation condition.

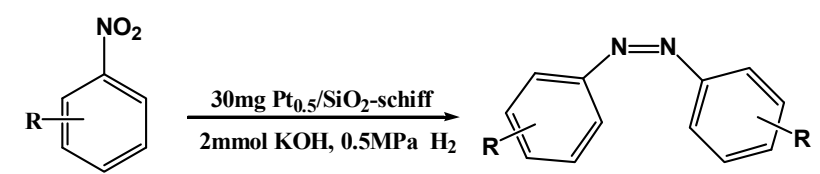

Scheme 2. Hydrogenation of different substituted nitrobenzenes to form Aazo over Pt catalyst.

Table 3. Hydrogenation of different substituted nitrobenzenes over Pt catalyst.

\begin{tabular}{|c|c|c|c|c|c|c|}
\hline \multirow{2}{*}{ Entry } & \multirow{2}{*}{$\mathbf{R}$} & \multirow{2}{*}{$\mathrm{T} /{ }^{\circ} \mathrm{C}$} & \multirow{2}{*}{ Conv. (\%) } & \multicolumn{3}{|c|}{ Sel. (\%) } \\
\hline & & & & DCAB & DCAOB & $p$-CNA \\
\hline 1 & $\mathrm{H}$ & 50 & 80.4 & 21.4 & 73 & 5.6 \\
\hline 2 & $\mathrm{H}$ & 90 & 99.0 & 85.6 & 3.3 & 11.1 \\
\hline 3 & $p-\mathrm{CH}_{3}$ & 50 & 95.9 & 48.1 & - & 51.9 \\
\hline $4^{\mathrm{a}}$ & $p-\mathrm{CH}_{3}$ & 90 & 99.0 & 87.0 & - & 13.0 \\
\hline 5 & $m-\mathrm{Cl}$ & 50 & 97.6 & 89.7 & 2.0 & 8.3 \\
\hline 6 & $p-\mathrm{Br}$ & 50 & 98.8 & 75.6 & 9.1 & 15.3 \\
\hline
\end{tabular}

\section{Materials and Methods}

\subsection{Catalyst Synthesis}

$\mathrm{SiO}_{2}$-Schiff: $\mathrm{SiO}_{2}$-Shiff was synthesized according to our previously reported procedure [43], in which the aldimine condensation of (3-aminopropyl)-triethoxysilane (APTES) with formaldehyde was involved. Typically, a HCHO solution $(10 \mathrm{~mL}, 37 \%)$ was dripped into an APTES aqueous solution $\left(500 \mathrm{~mL}, 0.12 \mathrm{~mol} \times \mathrm{L}^{-1}\right.$ ) while stirring at $40^{\circ} \mathrm{C}$ for $1 \mathrm{~h}$. A white precipitate formed, which was filtered and washed with deionized water. And then, the precipitate was aged at $150^{\circ} \mathrm{C}$ for $12 \mathrm{~h}$ in a Teflon-lined autoclave (Dalian, China). After cooling down to room temperature, a stable Schiff-base functionalized $\mathrm{SiO}_{2}$ support was obtained after by filtering, washing with an excess amount of deionized water, and then drying in vacuum (Shanghai, China) at $120^{\circ} \mathrm{C}$ for $12 \mathrm{~h}$.

$\mathrm{Pt} / \mathrm{SiO}_{2}$-Shiff: Briefly, $0.5 \mathrm{~g} \mathrm{\textrm {SiO } _ { 2 }}$-Shiff was added into an ethanol solution of $\mathrm{H}_{2} \mathrm{PtCl}_{6} \times 4 \mathrm{H}_{2} \mathrm{O}$ $(0.032 \mathrm{mM}, 400 \mathrm{~mL})$, and the mixture was magnetically stirred at $80^{\circ} \mathrm{C}$ for $30 \mathrm{~min}$. Then, $15 \mathrm{~mL}$ of $\mathrm{NaBH}_{4}(20 \mathrm{mg})$ aqueous solution was added to reduce $\mathrm{H}_{2} \mathrm{PtCl}_{6}$ to platinum catalyst. After stirring for $1 \mathrm{~h}$, the solid was filtered and washed with an excess amount of deionized water. After drying in vacuum at $120^{\circ} \mathrm{C}$ for $12 \mathrm{~h}$, the $\mathrm{Pt} / \mathrm{SiO}_{2}$-Shiff catalyst was obtained.

$\mathrm{Pt} / \mathrm{SiO}_{2}$ : The silica support (with a Brunauer-Emmett-Teller (BET) surface area of $596 \mathrm{~m}^{2} \times \mathrm{g}^{-1}$ ) supplied by Qingdao University was calcined in air at $500{ }^{\circ} \mathrm{C}$ for $2 \mathrm{~h}$ to remove adsorbed water before used. The $\mathrm{Pt} / \mathrm{SiO}_{2}$ was prepared by incipient wet technique. Typically, $2 \mathrm{~mL} \mathrm{H}_{2} \mathrm{PtCl}_{6} \times 4 \mathrm{H}_{2} \mathrm{O}$ $(0.032 \mathrm{mM})$ aqueous solution was impregnated with $0.5 \mathrm{~g} \mathrm{SiO}_{2}$ to generate precursors containing $0.5 \mathrm{wt} \% \mathrm{Pt}$. The mixture was magnetically stirred for $2 \mathrm{~h}$ under room temperature and then aged for $24 \mathrm{~h}$, followed by drying in an oven at $120^{\circ} \mathrm{C}$ for $12 \mathrm{~h}$. The samples were calcined in air at $400^{\circ} \mathrm{C}$ for $3 \mathrm{~h}$ and reduced in a flowing $\mathrm{H}_{2} / \mathrm{Ar}$ mixture $\left(50 \mathrm{~mL} \times \mathrm{min}^{-1} ; 20 / 30 v / v\right)$ at $300^{\circ} \mathrm{C}$ for $3 \mathrm{~h}$. This final product was denoted as $\mathrm{Pt} / \mathrm{SiO}_{2}$.

\subsection{Catalyst Characterization}

Pt loadings of as-prepared catalysts were analyzed by inductively coupled plasma-atomic emission spectroscopy (ICP-AES). An X-ray diffraction (XRD) experiment was performed on a PW3040/60 X' Pert PRO (PANalytical, Almelo, Netherland) diffractometer (with CuKa X-ray source operated at $40 \mathrm{kV}$ 
and $50 \mathrm{~mA}$ ). High-angle annual dark-field scanning transmission electron microscopy (HAADF-STEM) images of samples were recorded with the FEI Tecnai G2 F30 S-Twin microscope (Thermo Fisher Scientific, Waltham, MA, USA) operated at $300 \mathrm{kV}$. Before a typical STEM experiment, the sample was dispersed into ethanol after grinding, and the suspension was deposited onto a clean carbon-enhanced copper grid and then dried in air. Fourier transform infrared (FT-IR) spectroscopy with a resolution of $4 \mathrm{~cm}^{-1}$ were acquired by Bruker tensor 27 (Billerica, MA, USA) equipped with a DLATGS detector. X-ray photoelectron spectroscopy (XPS) spectra were achieved under a vacuum pressure of $10^{-9}$ Torr, with a VG ESCALAB 250 (Thermo Fisher Scientific) equipped with a monochromated Al-Ka radiation source $(1486.6 \mathrm{eV})$, and the binding energy was scaled to the $\mathrm{C} 1 \mathrm{~s}(284.6 \mathrm{eV})$.

\subsection{Catalyst Evaluation}

Typically, a catalyst $(30 \mathrm{mg})$, p-CNB $(1.0 \mathrm{mmol})$, potassium hydroxide $(\mathrm{KOH})(2.0 \mathrm{mmol}$, 2.0 equivalence vs. the number of reaction substrate) was added to an ethanol solvent $(5 \mathrm{~mL})$. The reaction mixture was put in a $25 \mathrm{~mL}$ reactor and charged with $0.5 \mathrm{MPa} \mathrm{H}_{2}$. The reaction was conducted at $50{ }^{\circ} \mathrm{C}$ for a certain time. The product yield was quantified by gas chromatography (GC) with FID (Shanghai Tianmei, GC7900 (Shanghai, China) equipped with an HP-5 column $(30 \mathrm{~m} \times 0.32 \mathrm{~mm} \times 0.25 \mu \mathrm{m}))$.

For the recyclability test, the spent catalyst was isolated by centrifugation and then thoroughly washed with deionized water, toluene, and ethanol, and dried at $120^{\circ} \mathrm{C}$ in vacuum.

\section{Conclusions}

In summary, a facile and highly efficient synthesis process for Aazo formation has been developed using $\mathrm{Pt} / \mathrm{SiO}_{2}$-Schiff catalysts. Compared with the traditional $\mathrm{Pt} / \mathrm{SiO}_{2}$ nano-catalysts, this Schiff-base modified Pt nano-catalyst showed high selectivity for the Aazo. The interaction between Pt and Schiff base stabilized Pt NPs and tuned the electronic state of Pt, enhancing the catalytic activity and stability. This new route can also be applied for the fabrication of other Schiff based modified metal nanoparticles (such as $\mathrm{Pd}$ and $\mathrm{Au}$ ) by altering the metal precursors, showing promise in catalysis and other fields.

Supplementary Materials: The following are available online at http://www.mdpi.com/2073-4344/9/4/339/s1, Figure S1: TEM images and corresponding size distribution of $\mathrm{Pt}_{0.8} / \mathrm{SiO}_{2}-\mathrm{Shiff}(\mathrm{a}), \mathrm{Pt}_{0.5} / \mathrm{SiO}_{2}-\mathrm{Shiff}(\mathrm{b})$ and $\mathrm{Pt}_{0.3} / \mathrm{SiO}_{2}$-Shiff(c).

Author Contributions: Y.T. designed the project and performed the catalyst preparation, characterizations and catalytic tests. X.W. and H.W. proposed, planned, designed and supervised the project. M.W., Q.L., Y.S. and H.L. participated in beneficial discussion. C.L. and X.C. helped to polish the manuscript. All authors reviewed and commented on the manuscript.

Funding: This work was supported by the National Natural Science Foundation of China $(21676145,21377018$, 21872135) and the Fundamental Research Funds for the Central Universities (DUT18LK34).

Acknowledgments: We thank anonymous reviewers for helpful suggestions on the manuscript.

Conflicts of Interest: The authors declare no conflict of interest.

\section{References}

1. Qiu, J.; Xiao, J.; Tang, B.; Ju, B.; Zhang, S. Facile synthesis of novel disperse azo dyes with aromatic hydroxyl group. Dyes Pigm. 2019, 160, 524-529. [CrossRef]

2. Merino, E. Synthesis of azobenzenes: The coloured pieces of molecular materials. Chem. Soc. Rev. 2011, 40, 3835. [CrossRef] [PubMed]

3. Merino, E.; Ribagorda, M. Control over molecular motion using thecis-transphotoisomerization of the azo group. Beilstein J. Org. Chem. 2012, 8, 1071-1090. [CrossRef]

4. Neistadt, M.E. Educational Interpretation of "Cooperative Learning as an Approach to Pedagogy". Am. J. Occup. Ther. 1999, 53, 41-43. [CrossRef] 
5. Bamford, C.H.; Ledwith, A.; Yagci, Y. Synthesis and reactions of polymers with photoactive terminal groups: 2. New azo-initiator for the synthesis of polymers with $N$-acyldibenz $[b, f]$ azepine terminal units. Polymer 1978, 19, 354-356. [CrossRef]

6. Denizli, A.; Pişkin, E. Dye-ligand affinity systems. J. Biochem. Bioph. Methods 2001, 49, 391-416. [CrossRef]

7. Osman, M.Y.; Sharaf, I.A.; Osman, H.M.Y.; El-Khouly, Z.A.; Ahmed, E.I. Synthetic organic food colouring agents and their degraded products: effects on human and rat cholinesterases. Br. J. Biomed. Sci. 2004, 61, 128-132. [CrossRef]

8. Shimada, C.; Kano, K.; Sasaki, Y.F.; Sato, I.; Tsudua, S. Differential colon DNA damage induced by azo food additives between rats and mice. J. Toxicol. Sci. 2010, 35, 547-554. [CrossRef] [PubMed]

9. Cisnetti, F.; Ballardini, R.; Credi, A.; Gandolfi, M.T.; Masiero, S.; Negri, F.; Pieraccini, S.; Spada, G.P. Photochemical and Electronic Properties of Conjugated Bis(azo) Compounds: An Experimental and Computational Study. Chem. Eur. J. 2004, 10, 2011-2021. [CrossRef] [PubMed]

10. Van der Zee, F.P.; Cervantes, F.J. Impact and application of electron shuttles on the redox (bio)transformation of contaminants: A review. Biotechnol. Adv. 2009, 27, 256-277. [CrossRef]

11. Hong, Y.G.; Gu, J.D. Physiology and biochemistry of reduction of azo compounds by Shewanella strains relevant to electron transport chain. Appl. Microbiol. Biotechnol. 2010, 88, 637-643. [CrossRef]

12. Khayat, Z.; Zali-Boeini, H. Novel sugar-based azo dyes as multistimuli responsive supramolecular gelators and chemosensors. Dyes Pigm. 2018, 159, 337-344. [CrossRef]

13. Sandborn, W.J.; Hanauer, S.B. The pharmacokinetic profiles of oral mesalazine formulations and mesalazine pro-drugs used in the management of ulcerative colitis. Aliment. Pharmacol. Therap. 2003, 17, $29-42$. [CrossRef]

14. Fujita, S.; Suzuki, M.; Peisach, J.; Suzuki, T. Induction of hepatic microsomal drug metabolism by azo compounds: A structure-activity relationship. Chem. Biol. Interact. 1984, 52, 15-37. [CrossRef]

15. Sandborn, W.J. Rational selection of oral 5-aminosalicylate formulations and prodrugs for the treatment of ulcerative colitis. Am. J. Gastroenterol. 2002, 97, 2939-2941. [CrossRef]

16. Riedinger, A.; Guardia, P.; Curcio, A.; Garcia, M.A.; Cingolani, R.; Manna, L.; Pellegrino, T. Subnanometer Local Temperature Probing and Remotely Controlled Drug Release Based on Azo-Functionalized Iron Oxide Nanoparticles. Nano Lett. 2013, 13, 2399-2406. [CrossRef]

17. Kenawy, E.-R.; Aly, E.; Imam Abdel-Hay, F.; Abdeen, R.; Mahmoud, Y.A.-G. Synthesis and microbial degradation of azopolymers for possible applications for colon specific drug delivery I. J. Saudi Chem. Soc. 2011, 15, 327-335. [CrossRef]

18. Haghbeen, K.; Tan, E.W. Facile Synthesis of Catechol Azo Dyes. J. Org. Chem. 1998, 63, 4503-4505. [CrossRef]

19. Raicopol, M.; Andronescu, C.; Atasiei, R.; Hanganu, A.; Manea, A.M.; Rau, I.; Kajzar, F.; Pilan, L. Synthesis of conducting azopolymers by electrochemical grafting of a diazonium salt at polypyrrole electrodes. Synth. Met. 2015, 206, 84-91. [CrossRef]

20. Hutchins, R.O.; Lamson, D.W.; Rua, L.; Milewski, C.; Maryanoff, B. Reduction of aromatic nitro compounds with sodium borohydride in dimethyl sulfoxide or sulfolane. Synthesis of azo or azoxy derivatives. J. Org. Chem. 1971, 36, 803-806. [CrossRef]

21. Entwistle, I.D.; Gilkerson, T.; Johnstone, R.A.W.; Telford, R.P. Rapid catalytic transfer reduction of aromatic nitro compounds to hydroxylamines. Tetrahedron 1978, 34, 213-215. [CrossRef]

22. Bouoit-Montésinos, S.; Bassus, J.; Perrin, M.; Lamartine, R. Synthesis of new phenylazocalix[n]arenes $(n=4,5)$. Tetrahedron Lett. 2000, 41, 2563-2567. [CrossRef]

23. Gowda, S.; Gowda, D.C. Application of Lead and Ammonium Formate as a New System for the Synthesis of Azo Compounds. Synthesis-Stuttgart 2002, 4, 460-462. [CrossRef]

24. Moglie, Y.; Vitale, C.; Radivoy, G. Synthesis of azo compounds by nanosized iron-promoted reductive coupling of aromatic nitro compounds. Tetrahedron Lett. 2008, 41, 1828-1831. [CrossRef]

25. Khan, F.A.; Dash, J.; Sudheer, C.; Gupta, R.K. Chemoselective reduction of aromatic nitro and azo compounds in ionic liquids using zinc and ammonium salts. Tetrahedron Lett. 2003, 44, 7783-7787. [CrossRef]

26. Grirrane, A.; Corma, A.; Garcia, H. Gold-Catalyzed Synthesis of Aromatic Azo Compounds from Anilines and Nitroaromatics. Science 2008, 322, 1661-1664. [CrossRef]

27. Wang, J.; Hu, L.; Cao, X.; Lu, J.; Li, X.; Gu, H. Catalysis by Pd nanoclusters generated in situ of high-efficiency synthesis of aromatic azo compounds from nitroaromatics under $\mathrm{H}_{2}$ atmosphere. RSC Adv. 2013, 3, 4899-4902. [CrossRef] 
28. Hu, L.; Cao, X.; Shi, L.; Qi, F.; Guo, Z.; Lu, J.; Gu, H. A Highly Active Nano-Palladium Catalyst for the Preparation of Aromatic Azos under Mild Conditions. Org. Lett. 2011, 13, 5640-5643. [CrossRef]

29. Hu, L.; Cao, X.; Chen, L.; Zheng, J.; Lu, J.; Sun, X.; Gu, H. Highly efficient synthesis of aromatic azos catalyzed by unsupported ultra-thin Pt nanowires. Chem. Commun. 2012, 48, 3445-3447. [CrossRef]

30. Liu, X.; Li, H.Q.; Ye, S.; Liu, Y.M.; He, H.Y.; Cao, Y. Gold-Catalyzed Direct Hydrogenative Coupling of Nitroarenes To Synthesize Aromatic Azo Compounds. Angew. Chem. 2014, 126, 7754-7758. [CrossRef]

31. Corma, A.; Serna, P.; García, H. Gold Catalysts Open a New General Chemoselective Route to Synthesize Oximes by Hydrogenation of $\alpha, \beta$-Unsaturated Nitrocompounds with $\mathrm{H}_{2}$. J. Am. Chem. Soc. 2007, 129, 6358-6359. [CrossRef]

32. Boronat, M.; Concepción, P.; Corma, A.; González, S.; Illas, F.; Serna, P. A Molecular Mechanism for the Chemoselective Hydrogenation of Substituted Nitroaromatics with Nanoparticles of Gold on $\mathrm{TiO}_{2}$ Catalysts: A Cooperative Effect between Gold and the Support. J. Am. Chem. Soc. 2007, 129, 16230-16237. [CrossRef]

33. Shi, W.; Zhang, B.; Lin, Y.; Wang, Q.; Zhang, Q.; Su, D.S. Enhanced Chemoselective Hydrogenation through Tuning the Interaction between Pt Nanoparticles and Carbon Supports: Insights from Identical Location Transmission Electron Microscopy and X-ray Photoelectron Spectroscopy. ACS Catal. 2016, 6, 7844-7854. [CrossRef]

34. Xiong, B.; Zhou, Y.; Zhao, Y.; Wang, J.; Chen, X.; O'Hayre, R.; Shao, Z. The use of nitrogen-doped graphene supporting Pt nanoparticles as a catalyst for methanol electrocatalytic oxidation. Carbon 2013, 52, 181-192. [CrossRef]

35. Lou, L.L.; Jiang, S.; Yu, K.; Gu, Z.; Ji, R.; Dong, Y.; Liu, S. Mesoporous silicas functionalized with aminopropyl via co-condensation: Effective supports for chiral Mn(III) salen complex. Micropor. Mesopor. Mat. 2011, 142, 214-220. [CrossRef]

36. Yu, C.; Yang, K.; Xie, Y.; Fan, Q.; Yu, J.C.; Shu, Q.; Wang, C. Novel hollow Pt-ZnO nanocomposite microspheres with hierarchical structure and enhanced photocatalytic activity and stability. Nanoscale 2013, 5, 2142. [CrossRef]

37. Liu, X.; Chen, N.; Han, B.; Xiao, X.; Chen, G.; Djerdj, I.; Wang, Y. Nanoparticle cluster gas sensor: Pt activated $\mathrm{SnO}_{2}$ nanoparticles for $\mathrm{NH}_{3}$ detection with ultrahigh sensitivity. Nanoscale 2015, 7, 14872-14880. [CrossRef]

38. Song, J.; Huang, Z.F.; Pan, L.; Li, K.; Zhang, X.; Wang, L.; Zou, J.J. Review on selective hydrogenation of nitroarene by catalytic, photocatalytic and electrocatalytic reactions. Appl. Catal. B 2018, 227, 386-408. [CrossRef]

39. Combita, D.; Concepción, P.; Corma, A. Gold catalysts for the synthesis of aromatic azocompounds from nitroaromatics in one step. J. Catal. 2014, 311, 339-349. [CrossRef]

40. Zhu, H.; Ke, X.; Yang, X.; Sarina, S.; Liu, H. Reduction of Nitroaromatic Compounds on Supported Gold Nanoparticles by Visible and Ultraviolet Light. Angew. Chem. Int. Ed. 2010, 49, 9657-9661. [CrossRef]

41. Guo, X.; Hao, C.; Jin, G.; Zhu, H.Y.; Guo, X.Y. Copper Nanoparticles on Graphene Support: An Efficient Photocatalyst for Coupling of Nitroaromatics in Visible Light. Angew. Chem. Int. Ed. 2014, 53, 1973-1977. [CrossRef]

42. Xiao, Q.; Liu, Z.; Wang, F.; Sarina, S.; Zhu, H. Tuning the reduction power of visible-light photocatalysts of gold nanoparticles for selective reduction of nitroaromatics to azoxy-compounds-Tailoring the catalyst support. Appl. Catal. B 2017, 209, 69-79. [CrossRef]

43. Liu, Q.; Yang, X.; Li, L.; Miao, S.; Li, Y.; Wang, X.; Huang, Y.; Zhang, T. Direct catalytic hydrogenation of $\mathrm{CO}_{2}$ to formate over a Schiff-base-mediated gold nanocatalyst. Nat. Commun. 2017, 8, 1407. [CrossRef]

(C) 2019 by the authors. Licensee MDPI, Basel, Switzerland. This article is an open access article distributed under the terms and conditions of the Creative Commons Attribution (CC BY) license (http://creativecommons.org/licenses/by/4.0/). 